\title{
Ranteveldplantegroei van Klerksdorp, Noordwes Provinsie, Suid-Afrika
}

\author{
E. van Wyk en S.S. Cilliers* \\ Departement Plant- en Bodemwetenskappe, Potchefstroomse Universiteit vir CHO, Potchefstroom, 2520 \\ G.J. Bredenkamp \\ Departement Plantkunde, Universiteit van Pretoria, Pretoria, 0001
}

Onwang 16 Oktober 1996: alanvalar 24 Jamuarie 1997

\section{UITTREKSEL}

In hierdie projek word die plantegroei van die gefragmenteerde ranteveld in die Klerksdorp munisipale gebied ondersock. Die motivering vir so 'n studie is dat hierdie gebiede bedreig word deur stedelike ontwikkeling soos nuwe residensiële gebiede, industriële ontwikkeling en ander versteurings. Hierdie plantegroeistudie vorm deel van 'n voorgestelde ekologiese basisplan vir die ontwikkeling en bewaring van hierdie gebied.

Relevés van die ranteveld is verwerk met TWINSPAN en Braun-Blanquet klassifikasieprosedures, terwy/ DECORANA gebruik is om gradiënte in die plantgemeenskappe te identifiseer. Die resultale toon 'n merkwaardige spesierykheid en besondere verspreiding van plantgemeenskappe. Klassifikasieresultate lewer 187 spesies in 3 gemeenskappe, 5 subgemeenskappe en 5 variante. Dit is hoofsaciklik as gevolg van die hoë diversiteit van die fisiese ongewing. Plantspesies kennerkend van versteurde stedelike ongewings het egter ook bygedra tot die spesierykheid. Dit wil voorkom of baie min van die oorspronklike natuurlike plantegroei verdwyn het. Ordeningsresultate toon dat plantegroeistruktutu; gronddiepte, oppervlakklipperigheid en grondtekstutr 'n groot invloed het op die verspreiding van die gemeenskappe terwyl versteuring in sommige gebiede tot die ontstan van spesifieke gemeenskappe gelei het.

Hierdie studie sal bydra tot die ontwikkeling van 'n sinvoller bewaringsgeoriënteerde bestutursplan vir die gebied. Baie mawe inligting oor die reaksie van natuurlike en indringerspesies in versteurde toestande is ook verkry.

\section{Abstract}

\section{Vegetation of the ridges of Klerksdorp, Northwest Province, South Africa}

This project investigates the vegetation of the fragmented ridges in the Klerksdorp Municipal area. Motivation for this study lies in the fact that these areas are being threatened by development, e.g. new residential areas, industrial sites and other dishurbances. This vegetation study forms part of a proposed base plan for the development and conservation of this area.

Relevés from the hills and ridges were processed by TWINSPAN and Brann-Blanquet classification procedures, while DECORANA was used to identify gradients in vegetation. The results show a remarkable richness in species composition and plant communities. In the classification 187 species were recorded in 3 communities, 5 sub-communities and 5 variants. This is partly a result of the great diversity in physical environment, bat invasive plant species enhanced species richess. It seems that very few of the original indigenous species were lost. Results from the ordination shows that vegetation structure, soil depth, surface rockiness and soil texture contribute greatly to the distribution of communities, while disturbance in some areas resulted in the development of specufic communities.

This study will not only contribute to the compilation of a guideline for a conservation orientated management plan for the area. but has also provided a weath of new knowledge on the reaction of indigenous and invasive plant species under disturbed conditions.

\section{INLEIDING}

Verstedeliking, simptomaties van die vinnig grociende menslike bevolking, het ernstige gevolge vir die volhoubare ontwikkeling van stedelike gebiede. As gevolg van die hoë konsentrasie mense en geboue in ' $n$ relatief klein gebied, vind groot veranderinge in dic biosfeer plaas. Sulke veranderinge dra by tot die agteruitgang van die natuurlike omgewing en die gevolglike agteruitgang van die lewenskwaliteit vir toekomstige generasies. Omdat stedelike oop ruimtes gedurig deur faktore tipies van die stedelike omgewing beïnvloed word en in direkte kompetisic is met nuwe stedelike ontwikkelings, word veroorsaak dat die natuurlike habitat in stede 'n deurlopend veranderende omgewing word. Dit lei meestal tot fragmentering van hierdic habitatte.' wat 'n verlaging in die biogeografiese potensiaal van oop ruimtes tot gevolg het. ${ }^{2}$
Plantegrocistudies in die stedelike omgewing is baic belangrik om ekologies eflekliewe oopruimte-beplanning in stedelike gebiede te verseker. ${ }^{3}$ Inligting verkry uit sulke ondersocke dra by tot die daarstelling van belangrike riglyne vir die bestuur van stedelike gebiede in Europa. ${ }^{4}$ Tot op hede is daar egter uiters min sulke studies in Suid-Alrika gedoen. Bestaande studies toon egter dat daar' $n$ behoelte vir 'n nuwe benadering ontstaan het ten opsigte van die beplanning en bestuur van oop ruimtes in stedelike gebiede. ${ }^{2 .}$ Daar word veral klem op die belang van biogeografiese riglyne tydens beplanning en bestuur van stedelike oop ruimtes gelê. ${ }^{5}$

Die fisiese omgewing en gepaardgaande biogeografiese faktore speel veral 'n groot rol in die studie. 'n Groep koppies wat deur die sentrale dele van Klerksdorp strek, vorm 'n baic belangrike landmerk in die stad. 'n Groot deel van hicrdic koppies is deur residensiële gebiede vanaf die omliggende 
natuurlike omgewing geisoleer, en sommige bestaan selfs uit lragmente tussen residensiële gebiede. Geen plantegroci-analise is al in hicrdic gebied gedoen nie, maar dit is ook van groot kultuurhistoriese belang vir die inwoners van Klerksdorp. Op sommige dele van die koppies is die oorblyfsels van klipkrale gevind en ou ashope en potskerwe kan steeds in hierdic gebiede gesien word. Die natuurlike skoonheid en kultuurhistoriese waarde van die gebied het lot die ontwikkeling van 'n voetslaanroete gelei, wat ongelukkig nic bevredigend benul word nie. Die volgende redes kan onder meer hiervoor aangevoer word:

- Onveiligheid wat gepaardgaan mel geïsoleerde voctslaanpaaie en die sporadiese ontstaan van inlormele behuising.

- Skending van die natuur as gevolg van crosic van informele deurgangroetes, en die onwettige storting van huishoudelike en tuinalval.

Om dic bewaringstatus van hierdie gebied te bevestig, is dit noodsaaklik om 'n volledige plantegroci-analise daarvan te doen. Daar gaan ook probeer word om die verspreiding van die plantgemeenskappe volgens die bestaande omgewingslaktore te verklaar en lig te werp op verdere bestuursvraagstukke aangaande die gebied.

\section{STUDIEGEBIED}

Die studiegebied is 'n groep gefragmenteerde koppies in die Klerksdorp munisipale gebied (figuur 1). Klerksdorp is in dic westelike gedeclte van die SuidAfrikaanse Hoëveld ongeveer $26^{\circ} 50^{\prime}$ suid $26^{\circ} 40^{\prime}$ oos geleë en kom voor in die Grasvelubioom en meer spesilick in dic droë sanderige Hoëveld Grasveld. ${ }^{7}$ Die studiegebicd beslaan ongeveer 254 hektaar.

\section{Klimaat}

Volgens die Köppen klassifikasie ${ }^{8}$ het Klcrksdorp 'n Bsklimaat. Dit is 'n kocl, droë steppe (ariede klimaat) met somerreënval. Die gemiddelde jaarlikse rec̈nval is $645 \mathrm{~mm}$."

Die gemiddelde daaglikse maksimum temperatuur oor 'n periode van 49 jaar is $25,6{ }^{\circ} \mathrm{C}$ en dic gemiddelde daaglikse minimum $9,3^{\circ} \mathrm{C}$. Die gemiddelde daaglikse maksimum temperatuur vir Desember en Januaric oortref $30^{\circ} \mathrm{C}$ en die daaglikse minimum temperatuur vir Julie is $0,0^{\circ} \mathrm{C} . .^{10}$

\section{Geologie}

In 'n studic oor die plantegroci van die Be-landtipe in die Wes-Transvaalse Grasveld word alangetoon dat die geologie van dié landipe meestal verteenwoordigend is van die Ventersdorp Supergroep en die Transvalal opeenvolging." Die geologie van Klerksdorp is verteenwoordigend van die Venterdorp Supergroep. Die gesteentes wat dagsoom op dic koppics behoort tot dic Makwassic Formasic wat deel tlitmaak van die Ventersdorp Supergroep. ${ }^{12}$ Die verspreiding van dagsome van dic Makwassic formasic in die westelike Hoèveld is egter beperk, met die Wolmaransstad omgewing, van die naaste gebiede waar hierdie formasic ook voorkom. Die geologie van dic sludiegebied stem dus nic ooreen met die meeste omliggende dagsome wat in dic natuurlike omgcwing rondom Klerksdorp voorkom nic.

Die Makwassic Formasie wat bestaan uit kwartsporliere en lawas vorm die prominente rante aan die westekant van dic

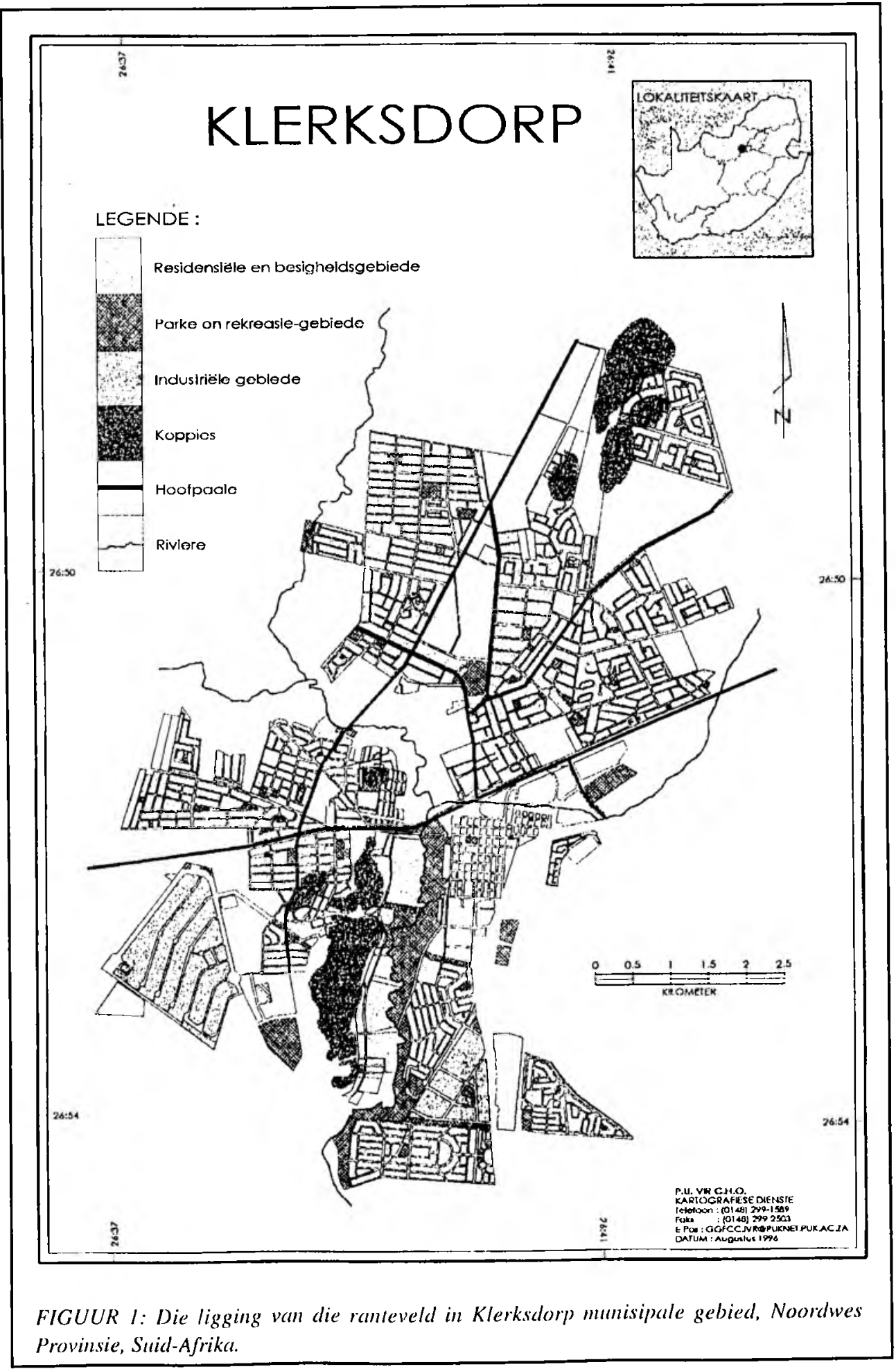


Schoonspruit, by Klerksdorp, en strek tot by die noordoostelike hoek van die plaas Kalferskraal 36. Die kwartsporfierlawa is nie ' $n$ intrusiewe liggaam nie, maar 'n lawaplaat. Dic Makwassie Formasie is in hierdie omgewing meer as $300 \mathrm{~m} \mathrm{dik}$. Die kwartsporfierlawa het 'n digte grys matriks met baie kwarts en veldspaatfenokriste. Die veldspaat is gewoonlik 'n plagioklaas wat wissel van albiet tot oligoklaas. Mikropertiet is ook teenwoordig in die kwartsporfierlawa. Daar is fyn poreuse as, kwartsporfiertuf, sowel as ander tuwwe en agglomerate in dele tussen die kwartsporfierlawa. ${ }^{13}$

\section{Grond}

Die grond van die studiegebied is geklassifiseer ${ }^{14}$ en die volgende tipes is geidentifiseer:

1. Baie vlak litosols, meestal van die Mispah vorm, wat voorkom op dic baie steil rotsagtige kranse en baic rotsagtige kruine.

2. Die vlak grond van die Glenrosa vorm kom meestal op die steil hange, geleideliker hellings en rotsagtige kruine voor.

3. Die dieper grond wat oor die algemeen op die gelyk dele tussen koppe of bo-op kruine voorkom, verteenwoordig meestal die Hutton vorm.

4. Klein gelokaliseerde areas waar water versamel, verteenwoordig meestal die Katspruit vorm.

\section{MATERIAAL EN METODES}

Relevés is saamgestel in 48 ewekansig gestratifiseerde persele. Stratifisering is op 1:10 000-skaal lugfoto's gedoen, op grond van relatief homogene fisiografiese en fisionomiese eenhede. Perseelgroottes is vasgestel op $16 \mathrm{~m}^{2}$ vir grasvelde en $100 \mathrm{~m}^{2}$ vir boomvelde soos voorgestel vir die grasveldbioom. ${ }^{15}$ In elke perseel is alle spesies wat tydens die opnametydperk identifiseerbaar was, genoteer. Die bedekkingswaardes van elke spesie is volgens die Braun-Blanquet skaal aangeteken. ${ }^{\text {to }}$ 'n Ontleding van floristiese data is gedoen d.m.v. 'n statistiese klassifikasietegniek, TWINSPAN ${ }^{17}$ en BBPC. ${ }^{18}$ Resultate van die klassifikasie is verfyn d.m.v. Braun-Blanquet prosedures om ekologies verantwoordbare plantgemeenskappe te identifiseer. Die finale resultate is in 'n fitososiologiese tabel aangebied. Vir ordening van die floristiese data is van DECORANA' ${ }^{19}$ gebruik gemaak. Die taksons is korrek benaam. ${ }^{20}$ Indringerplante en onkruide is bepaal. ${ }^{21}$ Die verspreiding van die plantgemeenskappe is nou geassosieer met die topografie, daarom is ' $n$ aantal terreintipes geidentifiseer om die ligging van dic plantgemeenskappe volgens die topografie te illustreer (figuur 2).

Die verspreiding van plantgemeenskappe word direk deur die omgewing bepaal, ${ }^{22}$ daarom is daar ook aandag gegee aan ' $n$ aantal habitatkenmerke. ${ }^{23.24}$

\section{Geologie}

Daar is soveel moontlik inligting oor verspreiding van die geologiese formasies ingewin om moontlik die plantgemeenskapsverspreiding daarvolgens te verklaar.

\section{Grond}

Studies oor die grondvorms lewer inligting oor omgewingsveranderings wat in die verlede plaasgevind het, maar steeds 'n sigbare effek het op die omgewing. Die toekomstige stedelike gebruik van die grond sal ook 'n verdere invloed op die ontwikkeling en ekologie van die grond hê..$^{25}$

Die spesifieke grondtipe en die gronddiepte tot op $1,5 \mathrm{~m}$ is aangeteken en fisiese en chemiese grondanalises is uitgevoer op verteenwoordigende grondmonsters.

Tydens die fisiese ontleding is die struktuursamestelling van die grond vasgestel. Die persentasie gruis $(2-75 \mathrm{~mm}$ in deursnee), sand $(0,05-2 \mathrm{~mm}$ in deursnee), leem $(0,05-0,002 \mathrm{~mm}$ in deursnee) en klei ( $<0,002 \mathrm{~mm}$ in deursnee) in die grond is bepaal. Chemiese analises sluit die bepaling van die $\mathrm{pH}\left(\mathrm{H}_{2} \mathrm{O}\right)$, elektriese geleidingsvermoë $(\mathrm{mS} / \mathrm{cm})$, hoeveelheid uitruilbare $\mathrm{K}^{+}, \mathrm{Na}^{+}, \mathrm{Mg}^{2+}$ en $\mathrm{Ca}^{2+}$ ( $\mathrm{mg} / 100 \mathrm{~g}$ grond) en die S-waarde as die som van die uitruilbare $\mathrm{K}^{+}, \mathrm{Na}^{+}, \mathrm{Mg}^{2+}$ en $\mathrm{Ca}^{2+}$ in.

Hierdie analises is gebruik om korrelasies te vind tussen die plantgemeenskappe en sekere grondkenmerke van die gebied. Die korrelasies is bepaal vir ' $n$ unieke stel grondveranderlikes en nie vir individuele veranderlikes nic. Daar is egter gelyktydig probeer om individuele veranderlikes wat belangrik mag wees vir die verspreiding van plantgemeenskappe te identifiseer. ${ }^{23}$

\section{Topografie}

Aspek, helling en hellingligging is belangrike omgewingsinligting oor elke perseel wat aangeteken is. Die topografiese posisie van elke plantgemeenskap (figuur 2 ) is aangeteken op ' $n$ aangepaste terreinvormskets. ${ }^{26}$ Die volgende terreintipes is geïdentifiseer.

$\begin{array}{lll}1 & : & \text { Plato / Gelykliggende kruin } \\ 2 & : & \text { Rotsagtige kruin } \\ 3 & : & \text { Steil, rotsagtige hang } \\ 4 & : & \text { Geleidelike middelhelling/pediment } \\ 5 & : & \text { Dreineringsgebiede }\end{array}$

\section{RESULTATE}

\section{KLASSIFIKASIE}

Die klassifikasie lewer drie plantgemeenskappe, vyf subgemeenskappe en vyf variante op. Uit die fitososiologiese tabel (tabel 1) word die volgende plantegroei-eenhede onderskei :

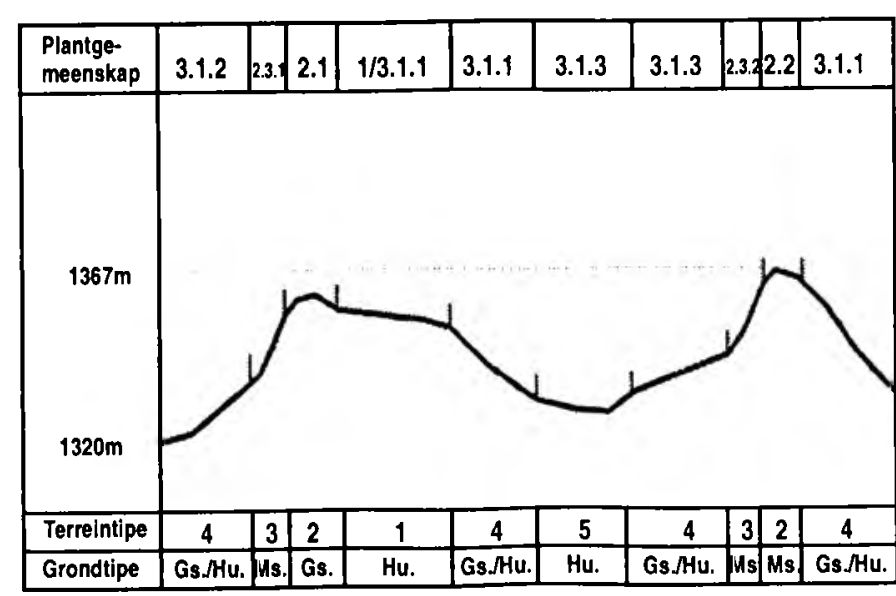

FIGUUR 2 : Die ligging van die plantgemeenskappe op die topografiese terreintipes in die studiegebied (aangepaste terreinvormskets $\left.^{26}\right)$.

Legende: Gs. = Glenrosa $H u:=$ Hutton Ms. $=$ Mispah 
TABEL 1 'n Fitososiologiese tabel van die plantegroei op die gefragmenteerde ranteveld in die Klerkdorp munisipale gebied, Noordwes Provinsie, Suid-Afrika






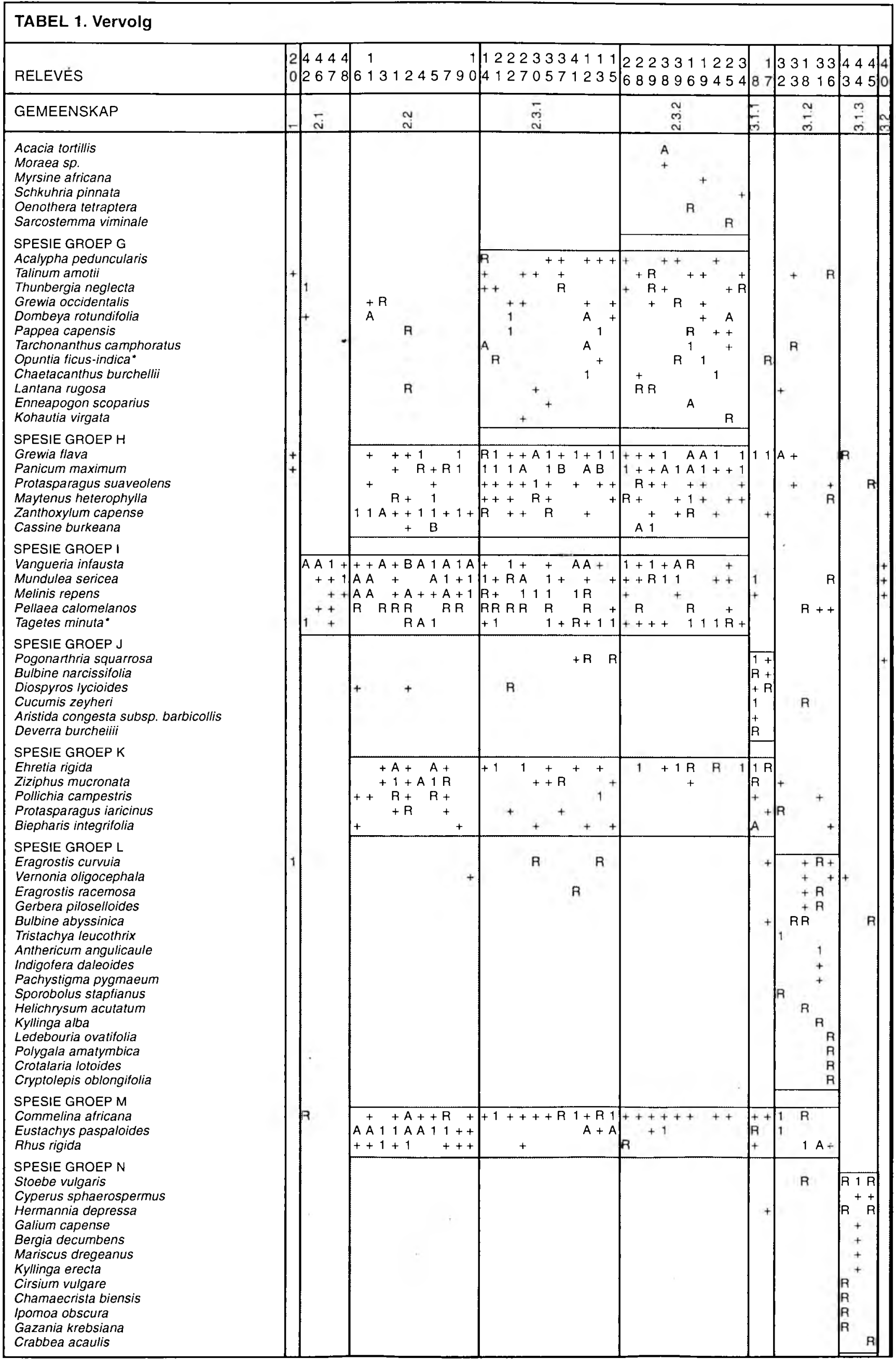




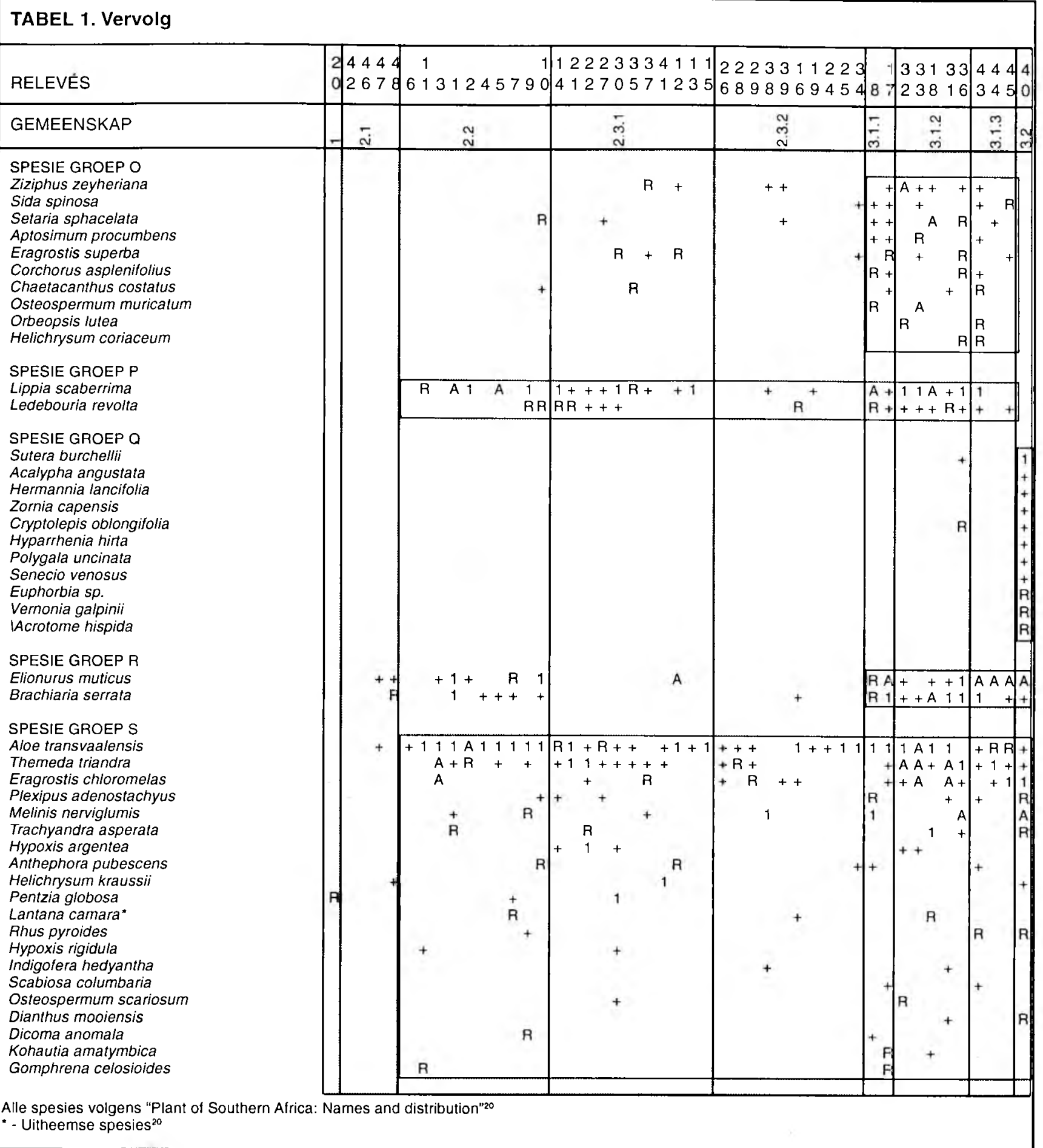

1. Cynodon dactylon - Opuntia imbricata gemeenskap

2. Mundulea sericea - Vangueria infausta gemeenskap

2.1 Aristida junciformis - Pavetta zey/heri subgemeenskap

2.2 Melinis repens - Scolopia zeyheri subgemeenskap

2.3 Acalypha peduncularis - Grewia flava subgemeenskap 2.3.1 Acacia caffra variant

2.3.2 Acacia robusta - Carissa bispinosa variant

3. Brachiaria serrata - Elionurus muticus gemeenskap

3.1 Lippia scaberrima - Ziziphus zevheriana subgemeenskap

3.1.1 Pogonarthria squarrosa-Bulbine narcissifolia variant

3.1.2 Eragrostis curvula variant

3.1.3 Stoebe vulgaris variant

3.2 Acalypha angustata - Sutera burchellii subgemeenskap

\section{BESKRYWING VAN GEMEENSKAPPE}

Tipies van dic plantegroei van Wes-Transvaal (Noordwes Provinsic), kan twee breë lisionomiese klasse, naamlik boomveld en grasveld onderskei word ${ }^{27}$ (figure 3 en 4). In die studiegebied kom die grasveld hoof saaklik op die plat kruine, gematigde hellings en dreineringsgebiede tussen koppe voor. Die boomveld word met die klipperiger en steiler gebiede geassosieer.

\section{Cynodon dactylon-Opuntia imbricata gemeenskap}

Dic Cynodon dacty/on - Opuntia imbricata gemeenskap is op die mees oostelike koppie in die suide van die studiegebied geleë (figuur I). Die grond in die gemeenskap is matig diep $( \pm 1 \mathrm{~m}$ ) en effens klipperig ( $5-10 \%$ ) maar stecds redelik gelykliggend (figuur 2). Dit hel'n hoë klei-inhoud en verteenwoordig neestal die Hutton grondvorm. 'n Aantal historiese klipkrale, oorblyfsels 
van kanonpersele en blokhuise wat uit die Anglo-Bocreoorlog (1899-1902) dateer, kom in dic gemeenskap voor. Ilierdic historiese aktiwiteite het gelei tol heelwat versteuring in die gebied. Die diagnostiese spesies van hierdie gemeenskap is dié van spesiegroep A (tabel 1) en is met die uitsondering van Cynodon dactylon, Lycium cinereum en Solanmm panduriforme almal uitheems. Die gemiddelde getal spesies wat per relevé voorkom, is 12 . Op sommige plekke groei Opantia imbricata baic dig en dring ook in die aangrensende gemeenskappe in. Die teenwoordigheid van die uitheemse kruide Boerhavia erecta en Physalis viscosa en die inheemse pioniergras $C$ ynodon dactylon dui daarop dat menslike versteurings soos vertrapping tans steeds voortduur. Hierdie gemeenskap behoort met groot omsigtigheid bestuur te word om te verhoed dat dit in ander gemeenskappe indring. Rehabilitasic van die gebied kan as 'n moontlike oplossing gesien word, waartydens Optuntia imbricata totalal verwyder word. Opantia imbricala is 'n verklaarde onkruid. ${ }^{2 x}, 29$ Die wet op bewaring van landbouhulpbronne vereis dan ook dat indien hierdic plante op 'n plaaseenheid en 'n stedelike gebied voorkom, dit verwyder moet word." Uit 'n ander oogpunt gesien, het genoemde versteuring gelei tot dic ontwikkeling van hierdie unicke gemeenskap, wat die totale spesiediversitcit van die ranteveld aansienlik verhoog

\section{Mundulea sericea - Vangueria infausta gemeenskap}

Dic grootste gedeclte van die studiegebied word deur hierdic plantgemeenskap beslaan (tabel 1). Die gemeenskap kom teen rotsagtige hange en kruine van rante voor (figuur 2). Die gronde is vlak $(<30 \mathrm{~cm})$ tot matig diep $( \pm 1 \mathrm{~m})$ en baic klipperig (> $10 \%)$. Die grond is kleicrig en die grondvorms is hoolsaaklik Mispah, Glenrosa en vlak Hutton. Dic fisionomicse samestelling wissel hoofsaaklik van digte struikveld tot hoomveld. Hierdie boomveld word gekenmerk deur die spesies van spesiegroep I (tabel 1). Die hoë bedekking van die inheemse struikspesics
Vangueria infausta en Mundulea sericea is kenmerkend van die gemeenskap. Die spesificke voorkoms van Tagetes minuta, Melinis repens en gedecltclike verspreiding van Commelina africana dui egter wel op 'n mate van versteuring in die gemeenskap. Alhoewel dit nic 'n hoë bedekking het nic, kom die varing Pellaea calomelanos wydverspreid in hierdic gemeenskap voor en word verbind me die klipperige en rotsagtige gebied wat ' $n$ ideale habitat skep. Hierdie gemeenskap toon sterk ooreenstemming met dic Vanguerio infausfae-Acacietum caffrae beskry! in die Bc-landtipe. " Klerksdorp is gelee in die Bc-landtipe-" $\mathrm{en}$ beide is wat die habitat betrel, beperk tot rotsagtige dagsome. Variasies in die spesiesamestelling van die verskeic subverdelings is die gevolg van die kleiner skaal waarop daar in hierdie studie gewerk is, in vergelyking met die grootte en verspreiding van die studiegebied in die Be-landtipe." Spesies wat veral in beide studies alangetref is, is Vengueria infausta, Celtis africana, Rhus rigida, Acacia caffra, Grewia flawa, Maytemas heterop/lylla en Ellretia rigida.

\subsection{Aristida junciformis - Pavetta zegheri subgemeenskap}

Hierdie subgemeenskap kom voor teen die steil noordelike hange en kruine (figuur 2) van die mees noordelike koppies (figuur 1). Dic grond is malig diep $( \pm 1 \mathrm{~m}$ ) en elfens klipperig $(5-10 \%)$. Die grond wissel van 'n kleileem tot 'n sandkleilecm en verteenwoordig hoolsaaklik die Glenrosa grondvorm. Daar word in die subgemeenskap 'n hoë mate van versteuring angetrel, alhoewel die versteuring nie so hoog is as in die geval van Gemeenskap 1 nic (figuur 4). Hierdic versteuring kan toegeskryf word aan beweiding deur vec. Die dominansic van Aristida junciformis toon dat die subgemeenskap oorbewei word ${ }^{29}$ Die struike en bome is baic yl verspreid op die kruin, moontlik vanweë vertrapping en kompaksic wat voortspruil uit langdurige oorbeweiding. Heelwat ou gruisgroewe kom ook in die subgemeenskap voor wat wel ook 'n mate van menslike versteuring in

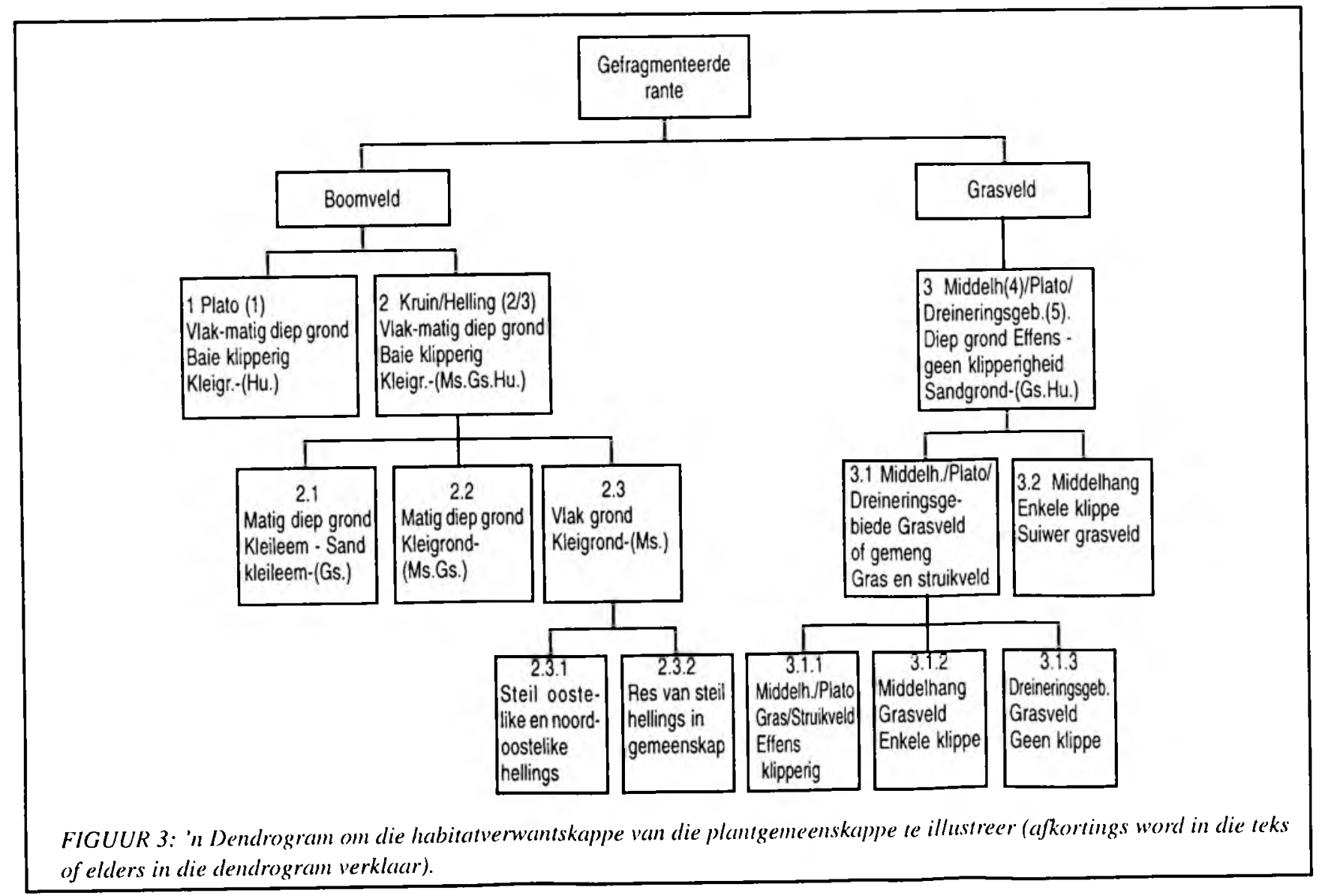


die verlede aandui. Hierdie koppies is die enigste in die studicgebied wat nic geïsoleer is van aangrensende koppies in dic natuurlike veld nic en stem ooreen mel die Pavello zeyheri Vanguerietum infaustae beskryf in dic Ba-landtipe in die WesTransvaalse grasveld. ${ }^{30}$ Spesies van Klerksdorp wat ooreenstem met die spesies van hierdic assosiasic is Pavella zeyheri, Tapiphyllam parvifolium, Indigofera comosa, Rhus leptodictya en Rhus magalismontana. Die genoemde spesies, asook Aristida junciformis, Adromischus umbraticola en Eragrostis trichophora is diagnosties van hierdie subgemeenskap. Die gemiddelde getal spesies wat in die gemeenskap per relevé voorkom, is 14 .

\subsection{Melinis repens - Scolopia zeyheri subgemeenskap}

Hierdie subgemeenskap is hoolsaaklik beperk tol die hange en kruine (figuur 2) van dic mees suidelike koppic (figuur 1). Die gronde is matig diep $( \pm 1 \mathrm{~m})$ en wissel van effens $(5-10 \%)$ tot baic klipperig (> $10 \%$ ), alhoewel rotsagtige gebiede ook voorkom, byvoorbeeld waar Scolopia zeyheri digle stande vorm. Die gronde is kleierig en behoort meestal tot dic Mispah en Glenrosa grondvorms. Hierdie suidelike koppic is nie van die natuurlike veld geissolecr nie, maar is ook nic aaneenlopend met enige koppe in die natuurlike veld nic. Diagnosticse spesies (spesiegroep C, tabel 1) in dic gemeenskap is die boomspesies Scolopia zeyheri en Olea europaea subsp. africana (beide dominant) en ander boomspesies soos Boscia albitrunca en Cellis africana wat ook voorkom. Dic dominante struikagtige Pavetta gardeniifolia en kruidagtige indikatorspesies, soos Abutilon sonneratianum en die varing Cheilanthes hirta kom ook voor. Die diagnostiese grasspesies wat voorkom is Eustachys paspaloides en in 'n mindere mate Eragrostis gummiflua. Daar kom gemiddeld 25 spesies per relevé voor.

\subsection{Acalypha pedancularis - Grewia flava subgemeenskap}

Hierdie wydverspreide subgemeenskap kom met dic uitsondering van die mees suidelike koppie, op al die koppics voor (figuur 1). Dit word angetref op baie vlak $(<30 \mathrm{~cm}$ diep) gebiede soos rotsagtige hange en klipperige kruine (figuur 2) en kom hoofsaaklik op die Mispah grondvorm voor. Hierdic subgemeenskap beslaan die grootste gebied van al die subgemeenskappe/ variante in die Mundulea sericea - Vangueria infausta plantgemeenskap. Diagnostiese spesies van hierdie subgemeenskap word in spesiegroep $\mathrm{G}$ (tabel 1) gelys en bestaan uit boomspesies soos Acacia caffia, Acacia robusta, Dombeya rotundifolia en Pappea capensis, struike soos Carrisa bispinosa, Grewia occidentalis en Tarchonanthus camphoratus en kruidagtiges soos Acalypha peduncularis, Talinum arnotii en Thumbergia neglecta, sowel as die uitheemse sukkulent Optmila ficus-indica, wat ook 'n verklaarde onkruid is. ${ }^{28}$ Ander belangrike spesies in hierdic subgemeenskap is die dominante struik, Grewia flava en die gras Panicum maximum (spesiegroep $\mathrm{H}$, tabel 1 ).

Binne die subgemeenskap kan tussen twee duidelike boomveldvariante onderskei word.

\subsubsection{Acacia robusta-Carissa bispinosa variant}

Die Acacia robusta - Carissa bispinosa variant, gekenmerk deur spesies van spesiegroep F (tabel 1), is beperk tot die steil oostelike en noordoostelike hange. Diagnostiese spesies van hierdic variant is bome soos Acacia robusta en Acacia torrilis, dic struike Carissa bispinosa, Plumbago auriculata en Euclea undulata subsp. myrtina, die kruidagtiges Barleria obtusa en Rhynchosia tolta, en die sukkulent Kalanchoe thyrsiflora. In hierdic variant kom daar gemiddeld 24 spesies per relevé voor.

\subsubsection{Acacia caffra variant}

Die Acacia calfra variant beslaan die oorblywende en grootste deel van die subgemeenskap. Spesies van spesiegroep D (label $1)$ is diagnosties vir die gemeenskap, en sluil spesies soos dic houtagtige Acacia caffra, kruidagtiges soos Coccinia sessilifolia, Pentarhinum insipidum en Felicia muricata en grasse soos Heteropogon comortus en Digitaria eriantha, in. Gemiddeld 19 spesies per relevé kom in die variant voor.

\section{Brachiaria serrata - Eliomurts muticuss gemeenskap}

Die Brachiaria serrata - Elionarus muticas gemeenskap is 'n grasveldgemeenskap, wat hootsaaklik voorkom op die geleiJelike middelhellings en pedimente, gelykliggende kruine boop koppies en die gelykliggende dreineringsgebiede tussen koppies (figuur 2). Dil word aangetref op diep ( $2 \mathrm{ml}$ ). sanderige gronde wal min tol elfens klipperig $(5-10 \%)$ kan wees. Dic gronde verteenwoordig meestal die Glenrosa en Hutton grondvorms. Elionurtss muticas en Brachiaria serrata is die enigste diannostiese spesies van die gemeenskap (spesiegroep R, label 1). Ander belangrike spesies in hierdie gemeenskap is die grasse Themeda riandra, en Eragrostis chloromelas en die sukkulent Aloe transvacalensis.

Die gemeenskap toon oorecnkomste met die Brachiaria serrata - Triraphis andropogonoides grasveld beskiyf in die Faan Meintjies Wildreservalat." Alhoewel die onderskeie onderafdelings van die gemeenskappe nic oorenstem nic, 100 die spesiesamestelling van die Brachiaria serrana - E/ionuras muticus gemeenskap sekere ooreenkomste mel dié van die Brachiaria serrala - Triraphis andropogonoides grasveld. Dic belangrikste verskil lussen die gemeenskappe is dall die Brachiaria serrata - Triraphis andropogonoides grasveld ${ }^{31}$ heelwat meer tipiese Bankenveldspesies heval byvoorbeeld Triraphis andropogonoides, Diheteropogon amplectens. Trachypogon spicatus, Elephantorhiza elephamina, Justicia anagalloides en Senecio coronatus. Spesies wat in beide gemeenskappe aangetref word, is Brachiaria serrata, Acalypha angustata, Hermannia lancifolia en Senecio venosus, wal veral ooreenstem met die spesiesamestelling van die Acalypher angustata - Sutera burchellii subgemecnskap. asook Dianthus: mooiensis, Pogonarlhria squarrosa, Eragrostis racemosa en Tristachya leucol/rix. Twee duidelike subgemecnskappe, wat verskil op grond van die kruidsamestelling, kan onderskei word.

\section{I Lippia scaberrima - Ziziphus zeyheriana subgemeenskap}

Hierdie subgemeenskap wissel van suiwer grasveld tot gemengde grass- en struikveld. Die gronde wissel van klipperig $(>10 \%)$ en matig diep $( \pm 1 \mathrm{~m})$ tot diep $(>2 \mathrm{~m})$ met 'n baic lac persentasie klipperigheid $(<5 \%)$. Spesies van spesiegroep $O$ (tabel 1) soos die platgroeiende struik Ziziphus zeyheriana kruide soos Sida spinosa, Aplosimum procumbens en Lippia scaberima en dic grasspesies Setaria sphacelata en Eragrostis superba is diagnosties van die subgemeenskap. Dric variante kan onderskei word op grond van spesiesamestelling en habitatsfaktore.

\subsubsection{Pogonarlhria squarrosa - Bulbine narcissifolia variant}

Die Pogonarthria squarrosa - Bulbine narcissifolia variant is 'n grasveld wat neig na 'n struikveld. Dit kom voor op gelykliggender matig diep $( \pm 1 \mathrm{~m})$, effens klipperige $(5-10 \%)$ gebiede. Dit is hoolsaaklik tol kruine beperk, maar kom ook soms op minder steil middelhellings voor (figuur 2). Spesies van spesiegroep J (tabel 1) onderskei hierdie variant van die 
ander variante in die subgemeenskap. Die diagnostiese spesies is Pogonarthria squarrosa, Bulbine narcissifolia en Diospyros lycioides. Ander spesies is die houlagtiges Grewia flava en Ehretia rigida. Die gemiddelde getal spesies wat per relevé voorkom is 34 . Die aantal spesies en die algehele afwesigheid van uitheemse indringerspesies, $100 n$ dat die variant in 'n natuurlike toestand is. Die hoc natuurlike voorkoms van struike staal dic posisie van die variant op die fisionomiese gradient in die ordening (figuur 4).

\subsubsection{Eragrostis curvula variant}

Die Eragrostis curvula variant is 'n grasveld wat voorkom teen matig diep $( \pm 1 \mathrm{~m})$, elfens klipperige ( $5-10 \%)$ middelhellings (liguur 2). Die diagnostiese spesies van spesiegroep L (tabel 1) in hicrdie variant is grasse soos Eragrostis curvula en Eragrostis racemosa en kruide soos Vernonia oligocephala en Gerbera piloselloides. Ander spesies soos Themeda triandra, Eragrostis chloromelas en Ziziphus zey/leriana is prominent in die variant. Daar kom gemiddeld 24 spesies per relevé voor.

\subsubsection{Stoebe vulgaris variant}

Die Stoebe vulgaris variant is 'n grasveld met grasspesies soos Setaria sphacelata en Elionurus muticus en diagnostiese kruidspesies soos Hermannia depressa, Galium capense en die diagnostiese indikator Stoebe vulgaris. Spesies van spesiegroep $\mathrm{N}($ tabel 1) is kenmerkend van hierdie variant. Die variant kom voor op diep (>2 $\mathrm{m}$ ) sandgrond wat glad nie klipperig is nic. Hierdic sandgrond is goed gedreineer en effens uitgeloog. Dic topografic veroorsalak egter dat dic afloopwater van die omliggende rante hier kan opdam wat vleivorming tot gevolg kan hê (lïguur 2). Dit verklaar die teenwoordigheid van sckere diagnostiese spesies van die familic Cyperaceac, soos Cypertıs sphaerospermus, Mariscus dregeanus en Ky/linga erecta. Hierdie variant het gemiddeld 19 spesies per relevé.

\subsection{Acalypha angustata - Sutera burchellii subgemeenskap}

'" Grasveld wat as yl verspreide kolle in die Acacia caffra variant in die mees noordelike hellings voorkom. Dit kom op baic geleidelike hellings hoof saaklik aan die suidoostelike kant van koppe voor (figuur 2). Die sanderige grond is diep (>2 m) met 'n lae persentasic klipperigheid (<5\%). Dic Hutton grondtipe

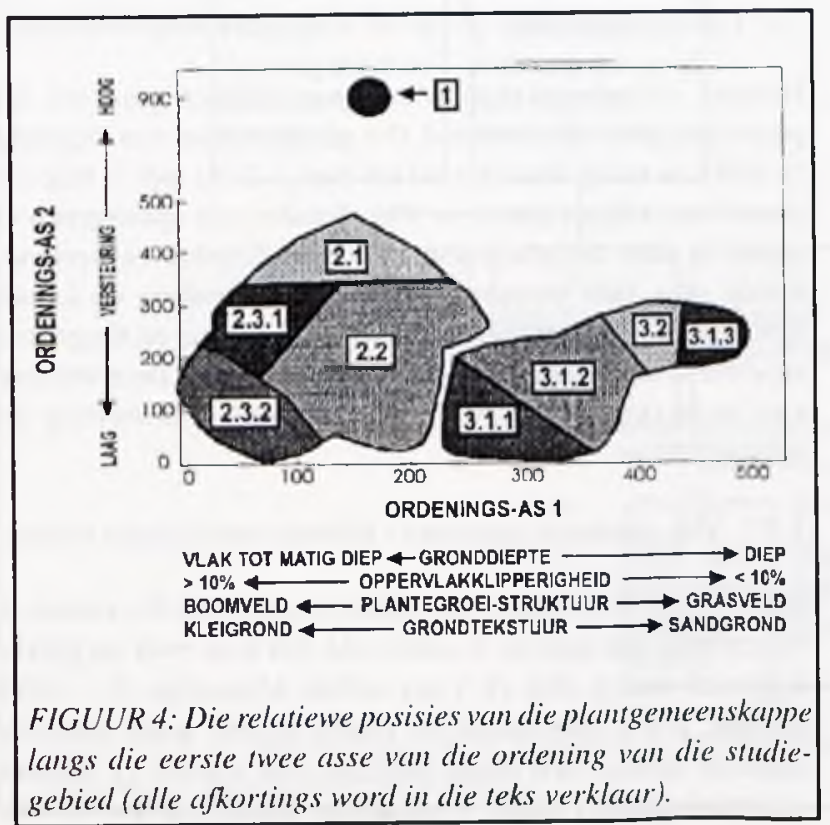

kom oorwegend voor. Diagnostiese spesies soos aangedui in spesicgroep Q (tabel I) is kruide soos Acalypha angustata, Sutera burchellii, Hermannia lancifolia, Zornia capensis en Cryplolepis oblongifolia en grasse soos Hyparhenia hirta. Ander spesies wal ook hoě bedekkingswaardes in die subgemecnskap het, is grasspesies soos Eragrostis chloromelas, Eragrostis lehmanniana, Elionurus muticus en Melinis nervighumis. Daar kom gemiddeld 32 spesies per releve in hierdie subgemeenskap voor.

\section{ORDENING}

In figuur 4 is die posisic van die verskillende plantgemeenskappe langs twee ordeningsasse aangetoon. Die plantgemeenskappe is duidelik beperk tot spesificke posisies in die verspreidingsdiagram. Langs die eerste ordeningsas word die grasveld aan die regterkant van die diagram aangetrel en die boomveld aan die linkerkant. Langs ordeningsas een word ook gradiente aangetrel wat verband hou mel gronddiepte en grondklipperigheid. Langs ordeningsas (wee is slegs 'n versleuringsgradiënt geỉdentifisecr. Die erg versteurde Cynodon dactylon Opantia imbricata gemeenskap (1) kom aan die bokant van dic diagram voor, tcrwyl dic res van die planlgemeenskappe aan die onderkant van die diagram voorkom. Grondtekstuurdata, verteenwoordigend van die onderskeie plantgemeenskappe is op 'n grondekstuurdiagram (liguur 5) aangeteken en het gevolglike plantegroei-eenhede op hierdie diagram verteenwoordig. Op die diagram kan 'n duidelike gradiën van onder na bo gesien word wat ooreenstem mel die verspreiding van die plantgemeenskappe op die eerste ordeningsas. Die geordende plantgemeenskappe het ooreengestem met die struktuurklasverspreiding van die grondontledings. Grondtekstuur dra dus heelwat by tot die verspreiding van die plantgemeenskappe in die studiegebied.

\section{BESPREKING}

Die verspreiding van die gemeenskappe in die studiegebied stem duidelik ooreen met die voorkoms van sekere habitatsfaklore. Sommige habilatsfaktore het sterk korrelasies getoon met die gemeenskapsverspreiding, terwyl ander habitatsfaktore geen korrelasies getoon het met die floristiese data nic. Dit wil voorkom of topografiese faktore en sommige fisiese grond-

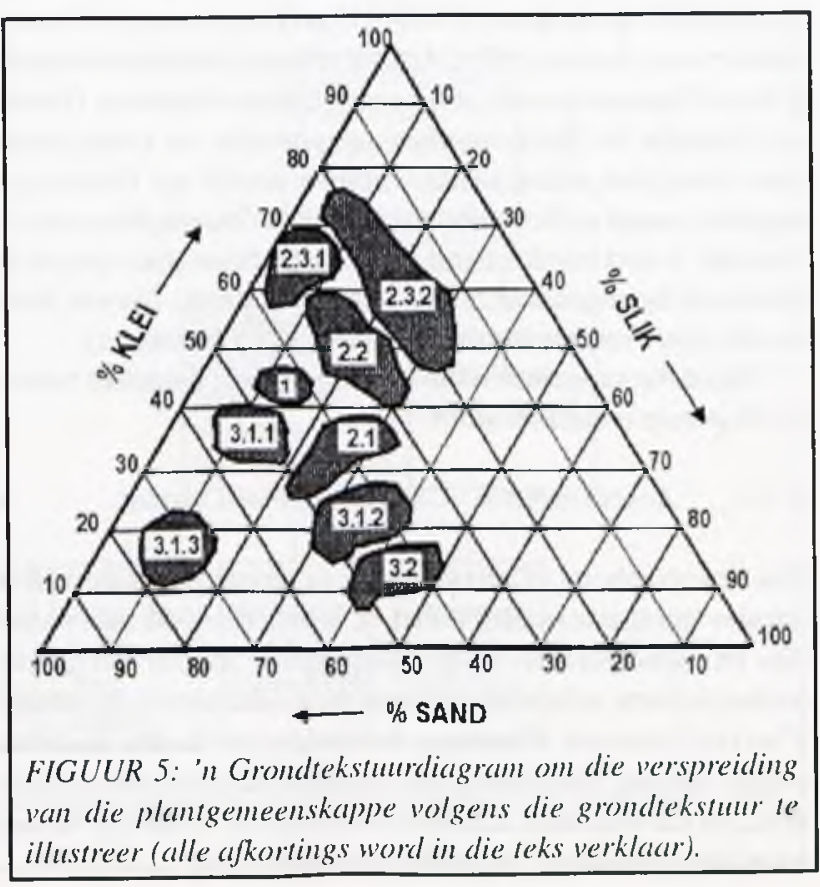


faktore soos grondtekstuur, gronddiepte en grondklipperigheid dic grootste invloed gehal het op die verspreiding van dic gemeenskappe. Die fisionomie van die gebied hel ook sterk gekorrelecr met lierdie habitalsfaktore. Versteuring, direk as gevolg van menslike aktiwiteite in die stedelike omgewing, het ook die ontstaan van dic Cynodon dactylon - Opantia imbricata gemeenskap (1) en die Aristida junciformis - Pavena zeyheri subgemeenskap (2.1) tot gevolg gehad. Resultate van chemiese grondanalises het geen korrelasies getoon met lloristiese data nic. Die moontlike verklaring hicrvoor kan wees dat die ranteveld' 'n homogene geologiese eenheid vorm. Enige chemiese grondveranderlikes alkomstig vanaf die geologiese verweringsproduk kan dus vir die hele sludiegebied konstant wees.

Die resultate toon 'n merkwaardige spesierykheid en besondere verspreiding van plantgemeenskappe. Dic gefragmenteerde aard van sommige dele van die koppies in die stedelike gebied het daartoe bygedra dat sommige spesics van die omliggende natuurlike omgewing ${ }^{11.31}$ in die studiegebied ontbreck, en gevolglik 'n unicke spesiesamestelling van die gemeenskappe in die studiegebied tot gevolg gehad het. Dit wil egter voorkom dat min van die oorspronklike natuurlike plantegroci verdwyn het. Dic hoë diversiteit van die fisiese omgewing het die spesicrykheid van die omgewing verhoog. Plantspesies kenmerkend van versteurde stedelike omgewings het egter ook bygedra tot dic spesierykheid. Dit kan duidelik gesien word aan dic aantal uithecmse spesies wat in die gebied gevestig het direk as gevolg van die invloed van die sledelike omgewing (tabel 1).

Daar is verwys na heel wat ooreenstemmende gemeenskappe soos gevind in studies in die Wes-Transvaalse Hoëveld (Noordwes Provinsie). Dit is daarom belangrik om daarop te let dat floristiese data steeds ooreenstem met wat te verwagte is in hierdie Hoěveld. Ten spyte van die invloed van die omliggende stedelike omgewing op dic studiegebied, het die gefragmentecrde koppies in Klerksdorp steeds in 'n relatief natuurlike toestand gebly, en bewaring van die gebied behoort 'n hö̈ prioriteit te wees.

Die studiegebied is onder druk van ' $n$ aantal kompeterende, alternaticwe grondgebruike. Hierdie gebruike bestaan hoofsaaklik uit behuising, rekreasic, landskapsbewaring en natuurbewaring.' Sekere kritcriums bestaan waarvolgens so 'n gebied vir grondgebruiksonering geëvalueer word. Tydens die evaluering van natuurlike gebiede vir bewaringsdoeleindes word kriteriums soos die voorkoms van skaars spesics, hoë spesicdiversiteit, geograliese vraagstukke soos gebiedsgrootte, natuurlikheid, produksic, nicherskepbaarheid, historiesc waarde en verteenwoordigbaarheid as van dic belangrikste faktoro bestempel. ${ }^{1.32 .33}$ As slegs sulke tradisionele kriteriums in ag geneem word tydens die evaluering van bewaringsgebiede, sal dit tot gevolg hê dat slegs gebiede aan die rand van stede bewaar sal word. Die ware betekenis van natuur in stede sal dan nie tot sy reg kom nic. Daar moet daarom ook aandag gegee word aan belangrike sosiale faktore soos publicke toeganklikheid, estetiese walarde, nabyheid aan die stedelike kern, vermoë om versteuring te weerstaan en voorkoms in gebiede wat min gebruik word. ${ }^{34}$

Hierdie gebied voldoen reeds aan heelwat van bogenoemde kriteriums, byvoorbecld natuurlikheid, esteticse en historiese waarde, en dic publicke tocganklikheid is gunstig vanweë dic wandelrocte.

Alhoewel die teenwoordigheid van heelwat uitheemse spesies 'n mate van versteuring aantoon, is die versteuring gelokaliseerd en die grootste dele van die koppe is in 'n natuurlike loestand. Dic mate van versteuring van sommige gemeenskappe vereis egter wel 'n toepaslike bestuurs- en rehabiliteringsprogram. Hierdie verslag kan dien as 'n basis vir die opstelling van so 'n bestuursprogram vir die gebicd. Dil is ook belangrik dat 'n geintegreerde en deelnemende benadering gevolg moel word om publicke bewuswording van hierdic unieke landmerk in Klerksdorp te bevorder.

\section{Summary}

\section{INTROIDUCTION}

Urbanisation, which is characteristic of a growing human population, not only contributes to the degradation of urban biospheres, but also leads to the degeneration of the quality of life for future generations in these areas. Urban open spaces are constantly in competition witl urban development and inlluenced by factors typical of the urban enviromment. Because of this, urban natural habitats are constantly changing environments. This in lurn leads to the fragmentation' of these habitats and a resulting reduction in the biogeographical potential of open spaces. ${ }^{2}$

Vegetation studies ensure the planning of ecologically sound urban open spaces. ${ }^{3}$ Information obtained from these studies has also been helpful in the compilation of guidelines for the management of urban areas in Europe. ${ }^{+}$

The physical environment and associated biogeographical lactors play an especially important role in this study. The study area includes a group of fragmented hilis and ridges in the Klerksdorp municipal areal (figure 1). Klerksdorp is situated in the western parts of the Soulh African Highveld ( $26^{\circ} 50^{\prime}$ South $26^{\circ} 40^{\prime}$ East ) which is classified under the Grassland hiome and more specifically the dry sandy Highveld Grassland. ${ }^{7}$ The study area includes an area of 254 hectare.

In order to determine the conservation status of the area, a complete vegetation analysis was necessary. The objective of this study was to interpret the distribution of the piant communities in terms of the existing environmental factors. This will answer questions which might arise, regarding the management of the area.

\section{MATERIAI. AND METHOIS}

Relevés were compiled in 48 stratified sample plots. Stratilication was done, using 1:50000 acrial photographs, on account of relative homogenous physiographical and physiognomical units. Plot sizes were fixed at $16 \mathrm{~m}^{2}$ for grassland communities and $100 \mathrm{~m}^{2}$ for woody communities. ${ }^{15}$ Cover abundance values according to the Braun Blanquel scale ${ }^{16}$, were recorded for all species in all relevés. Analysis of vegetation dala was done using the TWINSPAN classification algorithm ${ }^{17}$, and the BBPC suite. ${ }^{18}$ Relinements were made to the classification by means of Braun Blanquel procedures in order to identily plant communities. The result was a phytosociological table. The DECORANA ${ }^{19}$ ordination algorithm was also used to obtain an ordination. Taxons were correctly named. ${ }^{20}$ Invader plants and weeds were also identilied. ${ }^{21}$ A number ol land types were identified to illustrate the relation between topography and location of the plant community.(Figure 2). The environment directly influcnces the distribution of plant communities 22 , and therefore some attention was given to habitat characteristics.

\section{Soil :}

Soil type and depth were recorded up 10 a depth of $1.5 \mathrm{~m}$. Physical and chemical analysis of representative soil samples were conducted. 


\section{Topography:}

Aspect, slope and topographical position were important cuvironmental data recorded from each relevé.

\section{RESUITS}

\section{CLASSIFICATION}

Three major plant communities, five sub-communities and five variants were identified from the phytosociological table (table 1). The vegetation units are as follows:

\section{Cynodon dactylon - Optuntia imbricata community}

2. Mundulea sericea - Vangueria infausia community

2.1 Aristida junciformis - Pavena zeyheri sub-community

2.2 Melinis repens - Scolopia zeyheri sub-community

2.3 Acalypha pedancularis - Grewia flava sub-community 2.3.1 Acacia caffra variant

2.3.2 Acacia robasia - Carissa bispinosa variant

3. Brachiaria serrata - Elionurus muticas community

3.1 Lippia scaberrima sub-community

3.1.1 Pogonarthria squarrosa-Bubine narcissifolia variant

3.1.2 Eragrostis curvula variant

3.1.3 Stoebe vulgaris variant

3.2 Acalypha angustata - Sutera burchellii sub-community

Most of these communities are new communities, with the exception of the following:

- The Mundulea sericea - Vangueria infatsta community, which is similar to the Vanguerio infaustae - Acacietum caffra described in the Be land type."

- The Aristida junciformis - Pavetta zeyheri sub-community which is similar to the Pavetto zeyheri - Vanguerietum infaustae described in the Ba land type in the western Transvaal grassland. ${ }^{30}$

- The Brachiaria serrata - Elionurus muticus community which is similar to the Brachiaria serrata - Triraphis andropogonoides grassland described in the Faan Meintjies Nature Reserve. ${ }^{31}$

\section{ORDINATION}

The position of the respective plant communities is presented along two ordination axes in Figure 4. The plant communities are confined to specific areas in the distribution diagram. Gradients such as vegetation structure, soil depth, rockiness and soil texture were identified along the flrst ordination axis. A disturbance gradient is present along the second ordination axis. Soil texture data representative of the respective plant communities is presented in a soil texture diagram (Figure 5). The plant communities are in correlation with the soil texture data of the soil analysis.

\section{DISCUSSION}

The distribution of communities correlate clearly to areas with specific habitat characteristics. Topographical factors and soil factors such as soil texture, soil depth and rockiness secm to have the greatest influence on the distribution of communities.
The physiognomy also correlates strongly to these habitat factors. Results of the chemical analysis of soils showed no correlation with floristic data. A possible explanation for this feature is the homogenous geological structure of the ridges. The homogenous soil factor thus reflects the weathering of the homogcnous geological formation.

The results also show a remarkably high species diversity and unique distribution of communities. The fragmented nature of some parts of the hills and ridges in the area, contribute to the absence of certain species that do occur in the natural areas surrounding the city. It seems, however, that little of the natural vegetation has disappeared. ${ }^{11,31}$ The result is an unique composition of communities in the study area. The species richness is probably the result of the physical diversity of the area, and the presence of a large number of species characteristic ol disturbed urban environments (Table 1). The occurrence of the Cynodon dactylon - Opuntia imbricata community (1) and the Aristida junciformis - Paverta zeyheri sub-community (2.1) is probably due to disturbance, which is the direct consequence of human activity in the urban environment.

Relerence was made to several communities, identified in studies of the vegetation of western Transvaal Highveld. It is, therefore, important to note that the floristic data still correspond to those of the above-mentioned sludies. The fragmented hills and ridges of Klerksdorp have retained a relatively natural state, in spite of several unique influences in the area.

In the natural open spaces of the Klerksdorp municipal area a number of competitive, alternative land uses exists. These land uses include housing development, recreation, landscape and nature conservation.' Conservation of an area is evaluated according to certain criteria such as occurrence of rare species, high species diversity and certain geographical aspects namely surface area, naturalness, productivity, transformation potential, historical value and representation. ${ }^{1.32,33}$ But if only traditional criteria such as these are used, only the peripheral sections of the urban area would be retained in a natural condition. For this reason attention should be given to social factors such as public accessibility, aesthetic value, location, resilience and the presence of unutilised areas. ${ }^{34}$

The area meets many of the above mentioned criteria such as naturalness, acsthetic and historical value, and public accessibility, the latter due to the presence of a hiking trail.

The vegetation of the hills and ridges of Klerksdorp is mosily in a natural condition, but while most of the disturbance is localised, the disturbance of some of the communities requires careful management and rehabilitation. This report can serve as a basis for the implementation of such a rehabilitation program. Public awareness should also be encouraged in order to promote an integrated and participating approach to the preservation of this unique landmark in Klerksdorp.

\section{I.ITERATUURVERWYSINGS}

1. Spellerberg, I.F. (1992). Evaluation and Assessment for Comservation (Chapman \& Hall, London).

2. Roberts, D.C., Poynton, R.J. (1985). Central and peripheral open spaces: need for biological evaluation, S. Afr. J. Science, 81, 464466.

3. Roberts, D.C. (1993). The vegetation of municipal Dutban Floristic classification, Bothalia, 23(2), 27।-326.

4. Pyšek, P. (1995). Approaches to studying spontaneous settlement flora and vegetation in central Europe: a review. In Urban Ecology' as Basis of Urban Planning, Sukopp. H.Numata, M., Huber, A. eds. (SPB Academic Publishing bv, The Hague, The Netherlands) p 23.

5. Poynton, J.C., Roberts, D.C. (1985). Urban open space planning in 
South Africa: A biogeographical perspective, S. Afr. J. Science, 81 , 33-37.

6. Rutherford, M.C., Westfall, R.H. (1986). Biomes of Southern Africa - an objective categorization, Mem. bot. Surv. S. Afr:. 54, I-97.

7. Bredenkann, G.J., Van Rooyen, N. (1996). Dry Sandy Highveld Grassland. In Vegetarion of South Africa, Lesotho and Swaziland. Low, A. B., Rebelo, A. G. eds. (Dept. Enviromental Allairs \& Tourism, Pretoria) pp. 41.

8. Schultze, B.R. (1947). The Clinates of South Africa According 10 the Classifcations of Köppen and Thornthwaite, S. Afi: Geographical Journal, 29, 32-42.

9. Soil and Irrigation Research Institute. (1991). SIRI Report No. GB/ A/91/30. (Comp. F.G. Koch). Long Term Meteorological Data for the Highveld and Freestate Regions (Department Agricultural Development).

10. Weather Burcau. (1988). Climate of South Africa, climale statistics up 10 1984. WB 40 (Government Printer, Pretoria).

11. Bezuidenhout, H., Bredenkamp, G.J. (1991). The vegetalion of the Be land type in the western Transvial Grassland, South Africa, Phylocoenologia, 19(4), 497-518.

12. (The South African Commitee for Stratigraphy) SACS. (1980). Stratigraphy of South Africa. Part I. (Comp. L.E. Kemt). Lithostratigraphy of the Republic of South Africa, South West Africa/Namibia and the Republic of Bobuthatswana, Transkei and Venda (Department of Mineral and Energy Affairs)

13. Nel, L.T., Truter, F.C., Willemse, J. (1939). The geology of the country around Potchelstroom and Klerksdorp. An explanation of Sheet 61. Geological Survey. Union of South Africa. Dept, of Mines.

14. Grondklassilikasiewerkgroep. (1991). Grondklassifikasie: '" Taksomomiese Sisteem vir Suid-Afrika. Memoirs oor die Natuurlike Landbouhulpbronne van Suicl-Alrika $\mathrm{N} t .15$ (Departement van Landbouontwikkeling, Pretoria).

15. Bredenkamp, G.J., Theron, G.K. (1978). A Synecological acount of the Suikerbosrand Nature Reserve. I. The phytosociology of the Wilwatersrand geological system, Borhalia, 12, 513-529.

16. Meuller-Dombois, D., Ellenberg, H. (1974). Aims and Methods of vegetation Ecology (John Wiley \& Sons, New York).

17. Hill, M.O. (1979a). TWINSIAN - A FORTRAN program for arranging multivariate data in an ordered two-way table by classification of the individuals and atributes (Cornell University, New York).

18. Bezuidenhout, H.,Biggs, H.C., Bredenkamp, G.J. (1996). A process supported by the utility BBPC for analysing Braun-Blanquet dati on a personal computer, Koedoe, 39(1), 107-112

19. Hill, M.O. (1979b). DECORANA - A FORTRAN program for detrended correspondence analysis and reciprocal averaging
(Cornell University, New York).

20. Arnold, T.H., De Wet, B.C. (1993). Plants of Southern Africa: Names and distribution, Mem. bot. Surv. S. Afr. 62, 1 - 825 .

21. Wells, M.J., Balsinhas, A.A., Joffe, II., Engelbrech. V.M., Harding, G., Stirton, C.Il. (1986). A caltalogue of problem plants in Soulh Africa, Mem. bot. Surr. S. Afi.. 53, 1-6.58.

22. Bezuidenhout, H. (1988). '" Plantsosiologiese studie van die Mooirivier-oplanggebied, Tramsialal (M.Sc.-tesis, Potchefstroom Universiteit vir Christelike Hö̈r Onderwys).

23. Bredenkimp, G.J., Theron, G.K., Van Vuuren, D.R.J. (1983). Ecological interpretation of plant communities by classification and ordination of quantitative soil caracteristics. Bothalia, 1(3\& 4). 691-699.

24. Bredenkamp, G.J., Deutschländer, M.S., Theron. G.K. (1993). A phytosociological analysis of the Albizio harveyi - Eucleetum divinori from sodic bottomland clay soils of the Manyeleti Game Reserve, Gazankulu, South Africa, S. Afi. J. Bot. .59(1). 57-69.

25. Acy, W. (1990). Historical Approaches 10 Urban Ecology. In Urban Ecology, Sukopp, II., I lejny, S. eds. (The Hague: SPB Academic Publishing) p. 113

26. Land Types Scries. (1979). 2626 Wes-Rand. Prepared by the Soil and Irrigation Researdh Instimte. Pretoria. 1:2.50 000). (Government Printer, Pretoria).

27. Bezuidenhoul, H., Bredenkamp, G.J. (1990). A reconnaisince survey of the vegetation of the dolomitic region in the Potchelstroom - Ventersdorp - Randiontein area, South Africa, Phylocoenologia. $18,387-403$

28. Henderson, M., Fourie, D.M.C., Wells, M.J., Henderson, L. (1987) Verklaurde onkruide en uitheemse indringerplante in Suid-Afrike (1)epartement van Landbou en Watervoorsiening, Pretoria).

29. Van Oudshoom, F.P. (1991). Gidds tot Cirasse van Suid-Afrika (Nasionale Bockdrukkers, Kaapstad).

30. Bezuidenhoul, HI., Bredenkamp, G.J.. Theron, G.K. (1994). Syntaxonomy of the vegetation of the Ba land lype in the western Transvatal grassland, South Africa, S. Afr: J. Bot., 60(4), 214-224.

31. Bredenkamp. G.J., Bezuidenhout, H. (1990). The phytosociology of the Fatan Meintjies Nalture Reserve in the western Transvaal gransland, South Africa, S. Afi: J. Bot., 56(1), 54 - 64 .

32. Ratcliffe, D.A. (1977). A nature comservation review 2 vols. (Cimbriclge Universily Press, Cambridge).

33. Smith, P.G.R., Theberge, J.B. (1986). A review of eritcria for evaluating natural areas, Emirommental Manager, 10(6).715-734.

34. Gilbert, O.L. (1989). The Ecology of Urban Habirus (Chapmand \& Hlall Lid, London). 